\title{
Effects of Flange Size on Dividing Streamlines of Exterior Hoods in Cross Drafts
}

\author{
Rong Fung Huang, ${ }^{1}$ Gene Shin Liu, ${ }^{1}$ Yu-Kang Chen, ${ }^{2}$ Wen-Yu Yeh, ${ }^{3}$ \\ Chun-Wann Chen, ${ }^{3}$ and Chih-Chieh Chen ${ }^{4}$ \\ ${ }^{1}$ Department of Mechanical Engineering, National Taiwan University of Science and Technology, \\ Taipei, Taiwan \\ ${ }^{2}$ Department of Occupational Safety and Hygiene, Chang Jung Christian University, Kway Jen, Taiwan \\ ${ }^{3}$ Institute of Occupational Safety and Health, Council of Labor Affairs, Shijr City, Taipei, Taiwan \\ ${ }^{4}$ Institute of Occupational Medicine and Industrial Hygiene, National Taiwan University, Taipei, Taiwan
}

\begin{abstract}
Effects of flange size on the flow patterns of an exterior circular hood subject to the influence of various uniform cross drafts were studied in an apparatus consisting of hoodmodel/wind-tunnel assembly. The cross draft to suction velocity ratio covered the range from 0.056 to 0.792 . The flange width to hood diameter ratio spanned from 1.2 to 3.0. The hood equipped without flange was also probed. A two-component laser Doppler anemometer was used to measure the velocity field on the symmetry plane. The streamline patterns were obtained from the measured velocity data. The cross draft caused a capture envelope. The boundary of the envelope was described by a dividing streamline. It was found that the flange width presented complex effects on the capture envelope and the dividing streamline. Corresponding to a cross draft to suction velocity ratio, a critical flange width existed. If the flange width was smaller than the critical value, the dividing streamline would terminate at the downstream tip of the flange. The behaviors of the capture envelope and the dividing streamline of the hood in cross draft under different flange widths are presented and discussed.
\end{abstract}

Keywords cross draft, hood, limiting trajectory, stagnation point

Address correspondence to Rong Fung Huang, Department of Mechanical Engineering, National Taiwan University of Science and Technology, 43 Keelung Road, Section 4, Taipei, Taiwan, R.O.C.; e-mail: rfhuang@mail.ntust.edu.tw.

\section{INTRODUCTION}

$\mathrm{L}$ ocal exterior hoods have been used extensively to exhaust local airborne contaminants generated in a workplace. The performance and characteristics of local hoods with either a circular or rectangular opening have been studied by many investigators during the past few decades. ${ }^{(1-6)}$ (The flow features (around a local hood in a quiescent environment) studied most often have been the bell-shaped capture zone and the velocity distribution along a central axis.) The term "effective capturing" is usually quantified by the conventional concept of "capture velocity."(7) The velocities along the centerline axis of a local exhaust hood were usually measured to characterize the capture velocity. Garrison ${ }^{(8)}$ and Braconnier ${ }^{(9)}$ have provided a review on the centerline velocity gradients for plain and flanged local exhaust inlets. Garrison ${ }^{(10,11)}$ has also presented graphic data and fitted equations obtained from the centerline velocity measurements.

In practical use, drafts from open windows or doors, cooling air currents, moving persons or objects, blockage, and so on, may alter the shape and size of the bell-shaped capture zone. Theoretically, it has been known ${ }^{(12-19)}$ that the capture zone of an exterior hood under the influence of an uniform cross draft would present an envelope with a contour similar to a half Rankine body of revolution ${ }^{(20,21)}$ instead of the bell-shaped one.

A "limiting trajectory" (or "dividing streamline" termed by other investigators) described the outer boundary of the capture envelope. The suction opening of the hood was enclosed in the envelope of the half Rankine body of revolution so that all streamlines within the envelope led to the opening; those outside the envelope evolved to the downstream area. A contaminant, which originally was properly positioned for hood capturing, might move to the outside of the capturing envelope, exposed to the free cross stream, and eventually escape from the exhaust opening because the cross draft drastically alters the shape and the extent of the effective capture zone. In most cases, a cross draft with a small velocity of only few centimeters per second may be large enough to cause breakdown of the hood performance.

Huang et al. ${ }^{(22,23)}$ studied the flow field characteristics of circular and rectangular hoods in cross drafts by using the smoke streak, laser light sheet flow visualization method, and laser Doppler velocimeter. They found that the dividing streamlines at similar values of $R$ almost coincide with each other no matter 


\begin{tabular}{|ll|}
\hline NOMENCLATURE \\
$A$ & $\begin{array}{l}\text { area of hood opening }\left(\pi D^{2} / 4\right) \\
\text { diameter of hood opening, } 10 \mathrm{~cm}\end{array}$ \\
$Q_{s}$ & $\begin{array}{l}\text { volumetric suction rate of exhaust hood } \\
\text { cross draft to hood suction velocity ratio } \\
\left(=V_{c} / V_{s}\right)\end{array}$ \\
$R_{\text {critical }}$ & $\begin{array}{l}\text { critical value of cross draft to hood suction velocity } \\
\text { ratio corresponding to a certain value of } W / D\end{array}$ \\
$R e_{c}$ & $\begin{array}{l}\text { Reynolds number of cross draft based on hood } \\
\text { diameter }\left(=V_{c} D / \nu\right)\end{array}$ \\
$R e_{S}$ & $\begin{array}{l}\text { Reynolds number of suction flow based on hood } \\
\text { diameter }\left(=V_{s} D / \nu\right)\end{array}$ \\
$V_{c}$ & $\begin{array}{l}\text { velocity of cross draft } \\
\text { averaged suction velocity of exhaust hood } \\
V_{s}\end{array}$ \\
$W$ & $\begin{array}{l}\left(=Q_{s} / A\right) \\
\text { width of flange } \\
W_{\text {critical }}\end{array}$ \\
$x$ & $\begin{array}{l}\text { critical value of flange width corresponding to a } R \\
\text { coordinate along hood center line, originated at } \\
\text { center of hood opening } \\
\text { coordinate along direction of cross draft, origi- }\end{array}$ \\
$y$ & $\begin{array}{l}\text { nated at center of hood opening } \\
\text { kinematic viscosity of air } \\
\text { distance in } x \text { direction from origin to intersection } \\
\text { of hood centerline and dividing streamline } \\
\text { distance from center of hood opening to stagnation } \\
\text { point of dividing streamline }\end{array}$ \\
$\zeta$ &
\end{tabular}

what the Reynolds numbers of cross draft and suction are. The cross draft to suction velocity ratio $R$ is a nondimensional parameter that dominates the flow field. The correlated equations for the length scales of the limiting streamline provided convenient, quick tools for the design of a hood with a simple flat flange in cross draft. They also found that the centerline distance of the capture-envelope boundary obtained from the streamline method almost coincided with that obtained from the 50\% capture-efficiency method. ${ }^{(12)}$ Except for the characteristic geometry of the capture zone, the streamline method thus could also offer information of capture efficiency.

To locate the position of the stagnation point of a dividing streamline, Huang et al. ${ }^{(22,23)}$ employed a hood with a square flange of large size $W / D=3$ to avoid possible or unpredictable influences on the flow field. The stagnation points measured in their experiments were all located within the range of the hood flange. Two questions were left unanswered in their study: (1) How does the capture zone behave if the flange is shorter than the minimum requirement, and (2) Does a limiting value of flange size exist? Answers to these questions would be important to investigators who work on this subject. In this study, the authors continued previous work with various hood flanges of different sizes. The purpose of this study was to find out the effects of the flange size on the local hood operation in cross draft and to provide information for the flangedimension design requirement if the cross draft is to be taken into account.

\section{METHODS AND MATERIALS}

\section{Test Rig}

Figure 1 shows the experimental apparatus. The system included a circular hood model, a wind tunnel, peripheral devices, and instruments for measurements. The cross draft was supplied by an open-loop wind tunnel, which was described by Huang et al. ${ }^{(22,23)}$ The test section with dimensions of $50 \times 50 \times 120 \mathrm{~cm}$ was made of transparent Plexiglas ${ }^{\circledR}$ plates. The velocity range for stable operation of the wind tunnel was between $0.05 \mathrm{~m} / \mathrm{sec}$ and $20.0 \mathrm{~m} / \mathrm{sec}$. The turbulence intensity was less than $0.40 \%$ when the wind velocity $V_{c}$ was greater than $1.2 \mathrm{~m} / \mathrm{sec}$; it was $0.85 \%$ at $V_{c}=0.4 \mathrm{~m} / \mathrm{sec}$. A hot-wire anemometer, which was at times calibrated by a laser Doppler velocimeter, was used to measure and monitor the free-stream velocity of the cross draft. The accuracy of the freestream velocity measurement was about $0.5 \%$ of the reading.

Five sharp-edged square flanges made of acrylic plates were attached to a hood with circular opening of diameter $D=$ $10.0 \mathrm{~cm}$ for individual study. The widths of the square flanges used in this study were $1.2 D, 1.5 D, 2.0 D, 2.5 D$ and $3.0 D$. The thickness of the flanges was $4 \mathrm{~mm}$. The unflanged hood was also tested. The hood model was installed at the center of the test section and protruded perpendicularly through the ceiling plate $4 \mathrm{~cm}$ down into the test section. The maximum thickness of the wall boundary layer in current experimental range was estimated to be about $1.5 \mathrm{~cm}$ at the center of the test section so that no significant distortion of the flow field into the hood was caused by the effects of the wind tunnel walls. Positions were described in terms of a Cartesian coordinate system $(x$, $y$ ), as shown in Figure 2. The characteristic length scales ( $\eta$, $\zeta)$ were also shown in Figure 2.

Suction of the hood was provided via a centrifugal fan. The suction flow rate was measured by a Venturi ${ }^{\mathrm{TM}}$ flow meter, along with a calibrated electronic pressure transducer. The error of the suction flow rate measurement was less than $2 \%$ of the reading. The suction Reynolds number $R e_{s}$ was $3.55 \times 10^{4}$. The simulated cross-draft Reynolds number $R e_{c}$ was between $0.20 \times 10^{4}$ and $2.81 \times 10^{4}$. The cross draft-to-suction velocity ratio $R$ covers from 0.056 to 0.792 .

\section{Laser Doppler Velocimeter}

The velocity field was measured with a two-component laser Doppler velocimeter. The whole-spectrum laser light beam was provided by a $5 \mathrm{~W}$ argon-ion laser. Two color filters were used to allow blue and green laser beams of 514.5 and $488 \mathrm{~nm}$, respectively, to pass through. The blue and green laser beams were subsequently split and focused through an optical system. The dimensions of measuring volumes of the green and blue components were $0.075 \times 0.075 \times 0.680 \mathrm{~mm}$ and $0.071 \times 0.071 \times 0.645 \mathrm{~mm}$, respectively. The fringe separations of the green and blue components were $2.34 \mu \mathrm{m}$ and $2.22 \mu \mathrm{m}$, respectively.

The system was configured for backward scattering and was installed with a Bragg cell and two electronic frequency shifters for detection of direction ambiguity. Two electronic 


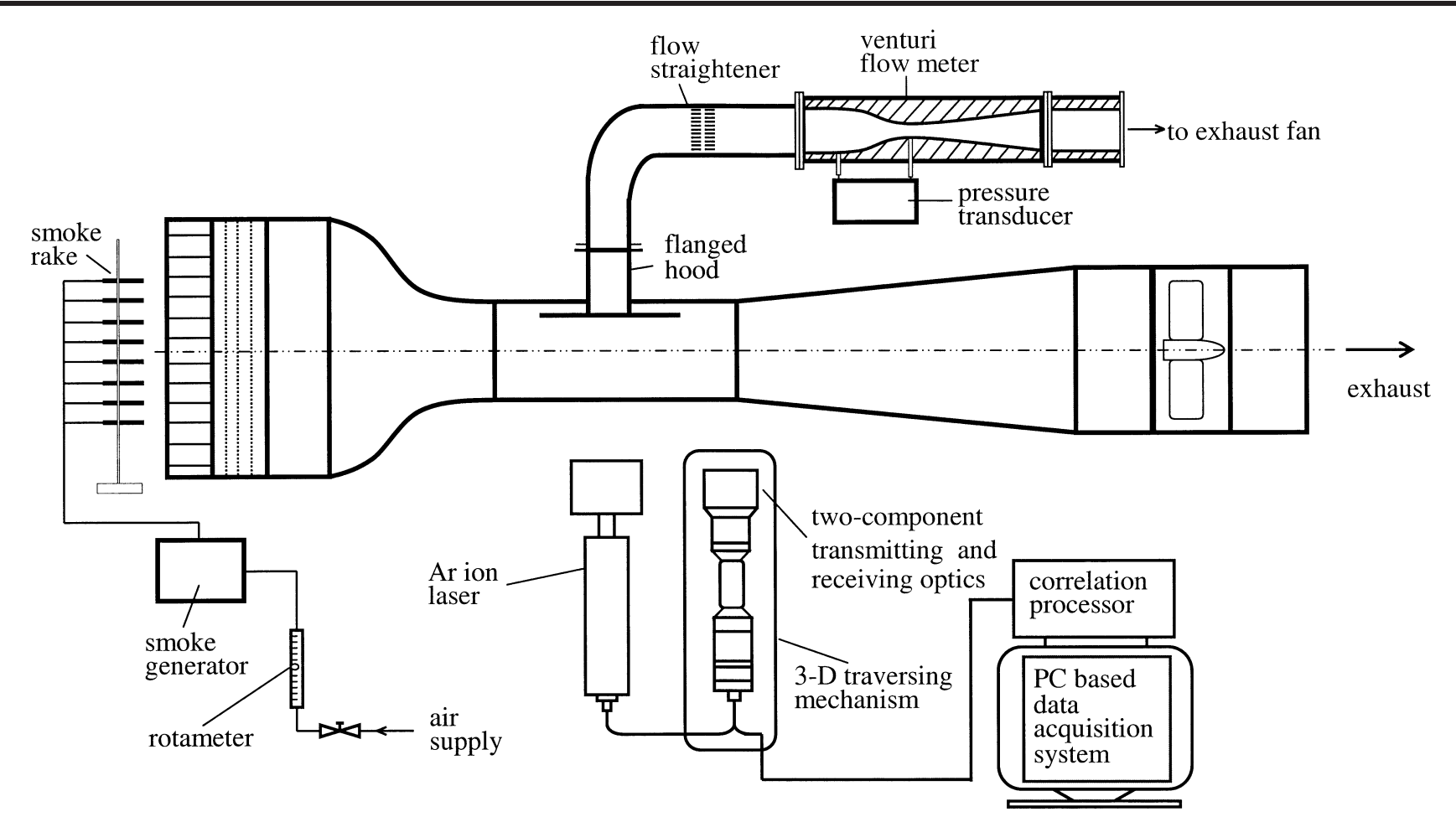

FIGURE 1. Experimental setup

correlators were used to process the frequency of the signals. The digital output of the correlation processors was fed into a data acquisition system. Each velocity data record consisted of 300 samples, about 1.5 seconds long. Uncertainty of the velocity measurements was estimated to be less than $\pm 0.5 \%$ of reading. Mineral oil mist was continuously seeded through a homemade smoke generator into the test section via a tube rake to scatter the laser light. The diameter of the oil mist particles, measured by a Malvern $2600 \mathrm{C}$ particle analyzer, was $1.7 \pm$ $0.2 \mu \mathrm{m}$. The density was $0.821 \mathrm{~g} / \mathrm{mL}$. Ignoring the effect of turbulent diffusion, the relaxation time constant was estimated to be less than $7.7 \times 10^{-5} \mathrm{sec}$, and the Stokes number was in the order of $10^{-6}$ within the range of experiment. Therefore, the seeding particles could properly follow the flow fluctuations at least up to $10 \mathrm{kHz} .^{(24)}$

\section{RESULTS AND DISCUSSION}

\section{Effects of Flange on Capture Envelope}

The measured velocity data in the symmetry planes of the flow fields at various cross flow to suction velocity ratios $R$ and flange sizes $W$ were converted into velocity vectors. The corresponding streamline patterns were obtained using the shooting method based on the measured velocity data. The resultant flow patterns are not presented in this article because the flow field characteristics are similar to those obtained by Huang et al. ${ }^{(22)}$ Only features of the effects induced by the flange size are summarized in the following paragraphs.

When a suction hood is subject to the action of a cross draft, a half Rankine body of revolution ${ }^{(22)}$ is formed. The dividing streamline evolves from an area far upstream, goes through the central axis at an intersection, rises up, then hits the lower surface of the downstream wing of flange perpendicularly to form a stagnation point if the cross draft to suction velocity ratio $R$ is larger than a certain value. For instance, at the flange width to hood diameter ratio $W / D=2.5$, the stagnation point would be formed on the lower surface of the flange if $R>0.075$. At $W / D=3.0$, the value of $R$ must be greater than 0.048 so that the stagnation point is formed on the flange surface. In the upper left part of the dividing streamline, all the streamlines evolving from upstream area lead eventually to the hood opening and construct a capture envelope. Theoretically, all the contaminants inside the capture envelope should follow the flow and be drawn into the hood opening if the dispersion effect is ignored. The capture envelope shrinks in size with the increase of the velocity ratio $R$. All the measured results of the normalized distance between the stagnation point on the flange and the central axis, $\eta / D$, as well as the normalized distance from the origin to the intersection of hood centerline and dividing streamline, $\varsigma / D$, follow the following equations that were obtained by Huang et al. ${ }^{(22)}$ if the dividing streamline hits the flange perpendicularly and the stagnation point is located on the lower surface of the flange.

$$
\begin{aligned}
& \frac{\eta}{D}=\frac{0.4285}{R^{0.4135}} \\
& \frac{\zeta}{D}=\frac{0.4073}{R^{0.5533}}
\end{aligned}
$$




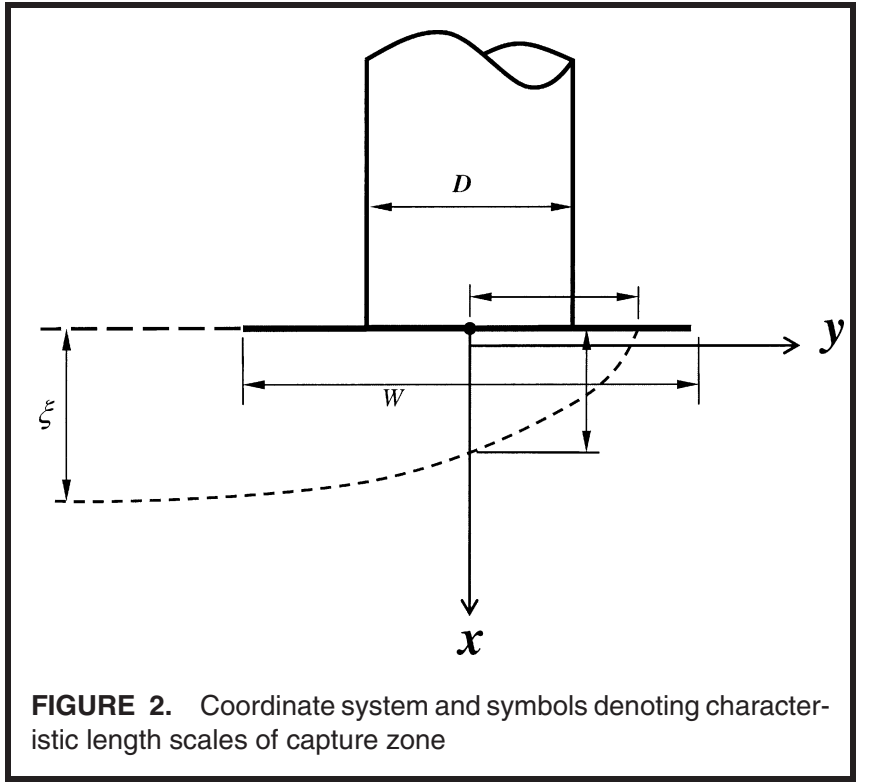

Corresponding to a $W / D$, if the cross draft to suction velocity ratio $R$ is smaller than a certain value, the path of the dividing streamline evolving from the upstream area would be modified and terminate at the downstream edge of the flange. Under this situation, the downstream flange edge, which can be treated as a stagnation point, is actually a separation point if the dividing streamline bifurcates to the upper and downstream regions of the flange. For instance, at $W / D=1.5$, the stagnation point would be located at the downstream edge of the flange if $R$ is smaller than 0.258 . At $W / D=1.2$, the situation occurs when $R$ is smaller than 0.443 .

Analyzing all the measured data in this study, it is found that if a hood is installed with a flange where the half flange width to hood diameter ratio $(W / D) / 2$ is larger than the value $\eta / D$ evaluated by Equation 1, the dividing streamline would hit the flange perpendicularly and the stagnation point would be located on the lower surface of the flange. Should a hood be equipped with a flange where the half flange width to hood diameter ratio $(W / D) / 2$ is smaller than the value $\eta / D$ evaluated by Equation 1, the stagnation point will stick to the downstream edge of the flange and thus $\eta / D=(W / D) / 2$. The unflanged hood was also studied. The most prominent difference of the dividing streamlines between the cases of the unflanged hood and the flanged hood is in the region around the stagnation point: the stagnation point of the unflanged hood is located at the downstream edge of the hood opening. No particular difference was observed in other parts of the flow field.

The curved lines in Figure 3 summarize the variations of dividing streamlines with $R$ at different flange conditions. At large $W / D$, as shown in Figure 3(a), the stagnation points of the dividing streamlines at $R_{1} \sim R_{5}$ where $R_{5}>R_{4}>R_{3}>$ $R_{2}>R_{1}$ are located on the downstream wing of the flange. If the half flange width to hood diameter ratio $(W / D) / 2$ is smaller than the corresponding values of $\eta / D$ for some $R \mathrm{~s}$,

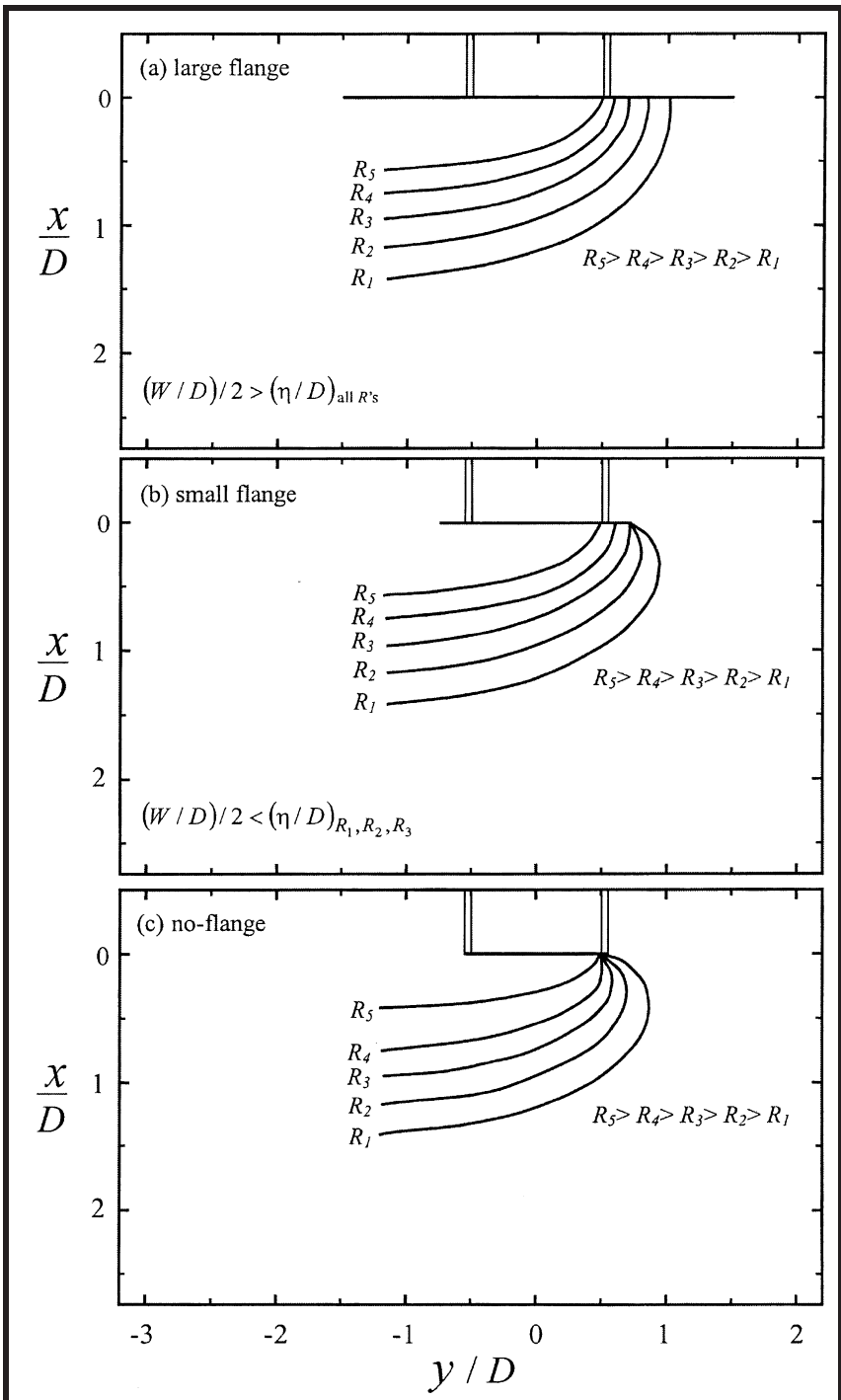

FIGURE 3. Curved lines summarizing variations of dividing streamlines with $R$ at different flange sizes

the dividing streamlines are modified as shown in Figure 3(b). If the hood is installed without flange, all the stagnation points merge to the downstream tip of the hood opening.

\section{Critical Flange Size}

Figures 4(a) and (b) show the variation of $\eta / D$ with $R$ and $W / D$, respectively. In Figure 4(a), all values of $\eta / D$ at $W / D=$ 3.0, 2.5, and 2.0 are located on the path of Equation 1, which is expressed by the dashed line. In other words, if $(W / D) / 2$ are greater than $\eta / D$, which are calculated by using Equation 1 with corresponding $R$, the measured data points of $\eta / D$ fall exactly to the locus of Equation 1. At $W / D=1.5$ and 1.2, that is, when $(W / D) / 2$ are smaller than or equal to the calculated values of $\eta / D$ with corresponding $R$ by using Equation 1, measured values of $\eta / D$ remain at $(W / D) / 2$. For a hood that is unflanged, $\eta / D$ remains at 0.5 at all $R$ s. At very large values of $R$, for example, $R=0.8$, all values of $\eta / D$ approach to 0.5 , 


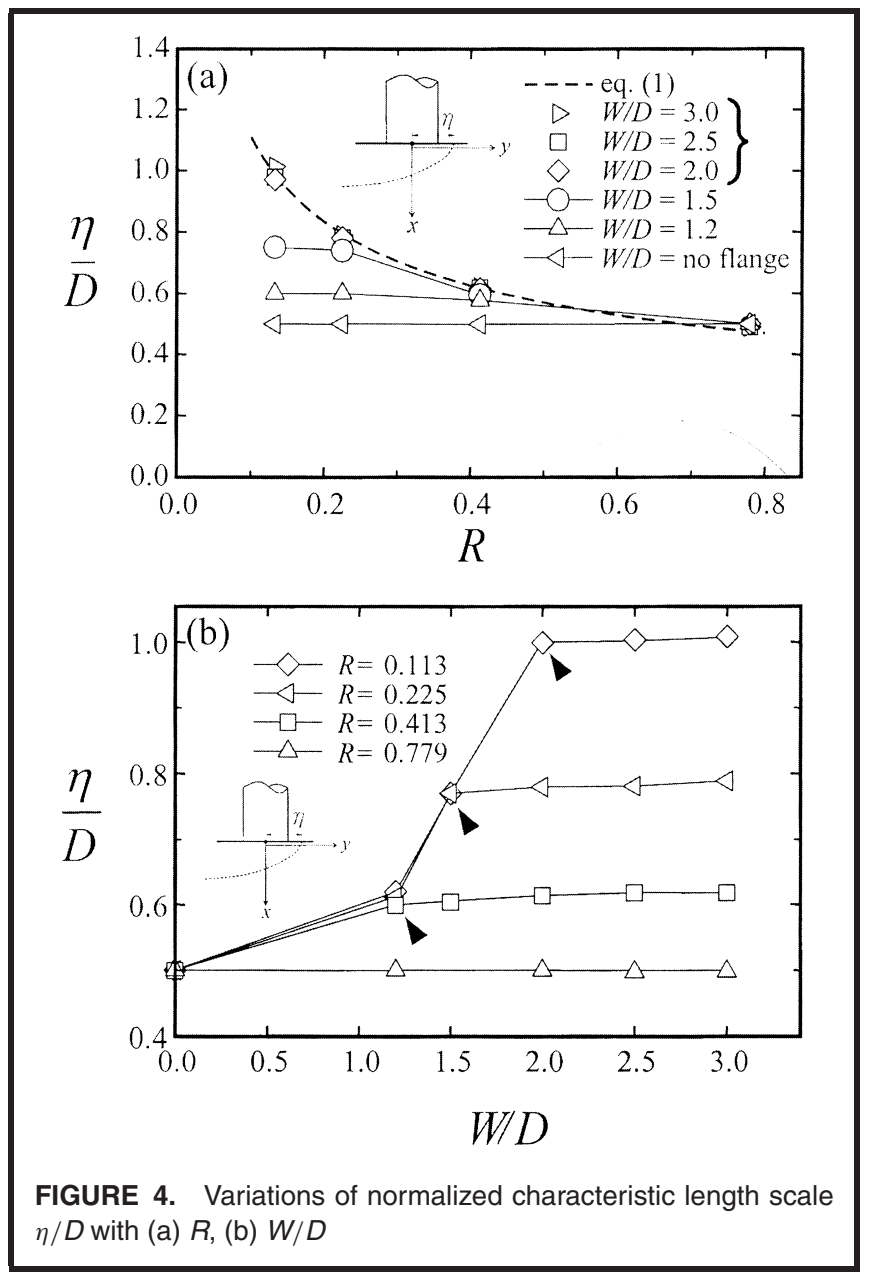

that is, the downstream tip of the hood inlet. Variations of $\eta / D$ with $W / D$ at various $R$ s can be directly traced on Figure 4(b). For each $R$, the value of $\eta / D$ remains constant when $W / D$ is greater than or equal to a critical value $W_{\text {critical }} / D$, which is indicated by the arrow heads. For $W / D<W_{\text {critical }} / D, \eta / D$ falls to a value of $(W / D) / 2$. Using Equation 1, the critical flange size $W_{\text {critical }}$ can be readily expressed by

$$
\frac{W_{\text {critical }}}{D}=\frac{0.8570}{R^{0.4135}}
$$

Inversely, a critical value of cross draft to suction velocity ratio $R_{\text {critical }}$ can be written as

$$
R_{\text {critical }}=\frac{0.6885}{(W / D)^{2.4184}}
$$

For a designated $W / D$, the dividing streamline will terminate at the downstream tip of the flange if the cross draft to suction velocity ratio $R$ is smaller than $R_{\text {critical }}$. An example of flange size design using Equations 3 and 4 is discussed in the following section.

Although not shown with a figure here, it is observed that if the flange width $W$ is larger than the critical value $W_{\text {critical }}$, the normalized distance from origin to intersection of hood centerline and dividing streamline, $\varsigma / D$, remains almost constant. When $W$ is smaller than the critical value, $\varsigma / D$ decreases a
TABLE I. Numerical Examples for Flange Size

\begin{tabular}{|c|c|}
\hline $\begin{array}{c}\text { Cross Draft to } \\
\text { Suction Velocity Ratio } \\
R=V_{c} / V_{s}\end{array}$ & $\begin{array}{c}\text { Recommended Minimum } \\
\text { Value of Flange Width } \\
\text { to Hood Diameter Ratio } \\
\frac{W_{\text {critical }}}{D}=\frac{\mathbf{0 . 8 5 7 0}}{R^{0.4135}}\end{array}$ \\
\hline 0.05 & 2.96 \\
\hline 0.10 & 2.22 \\
\hline 0.15 & 1.88 \\
\hline 0.20 & 1.67 \\
\hline 0.25 & 1.52 \\
\hline 0.30 & 1.41 \\
\hline 0.35 & 1.32 \\
\hline 0.40 & 1.25 \\
\hline 0.45 & 1.19 \\
\hline 0.50 & 1.14 \\
\hline
\end{tabular}
Design When the Effect of Cross Draft Is Considered

little. In other words, the distance between the origin to the intersection of hood centerline and dividing streamline is a little shortened if the flange width is smaller than the critical value corresponding to a $R$ value.

\section{Recommendations for Practical Use}

If a local exhaust hood is designed under the influence of a cross draft, the critical width of the attached flange can be calculated by using Equation 3 if a cross draft to suction velocity ratio is estimated. The designed width of the flange should be equal to or greater than the calculated critical value $W_{\text {critical }}$. If the flange width is smaller than the critical width $W_{\text {critical }}$, the capture envelope subject to a target cross draft will shrink appreciably in $\eta$, as shown in Figure 4(b). Risk of capture efficiency deterioration may be experienced because of the shrinkage of capture zone. If the critical cross flow to suction velocity ratio is to be estimated based on an existing hood, Equation 4 provides the tool for convenient use.

Table I lists numerical examples of recommended minimum values of flange width to hood diameter ratio corresponding to some $R$ values. Practitioners can refer to this table and estimate the minimum flange size for their designs if the effect of cross draft on the capture envelope is taken into consideration.

\section{CONCLUSIONS}

he effects of flange size on the characteristics of the capture envelopes and characteristic length scales in the flow field of a circular suction hood that is subject to a cross draft were studied. The following conclusions are drawn from the results.

- Corresponding to a certain cross draft to suction velocity ratio $R$, there exists a critical flange size $W_{\text {critical }}$, which can be evaluated by Equation 3. If the flange width to hood diameter ratio $W / D$ is smaller than the critical value $W_{\text {critical }} / D$, 
the dividing streamline will terminate at the downstream tip of the flange. In this case, the normalized distance between the stagnation point and the central axis, $\eta / D$, equals $(W / D) / 2$.

- Corresponding to a ratio $W / D$, there exists a critical cross draft to suction velocity ratio $R_{\text {critical }}$, which can be evaluated by Equation 4. Should the cross draft velocity in practical operation of the hood make the $R$ value smaller than $R_{\text {critical }}$, the dividing streamline would terminate at the downstream tip of the flange.

- If a hood in cross draft is not equipped with a flange, the stagnation point will stick onto the downstream tip of the hood opening.

- The influence of the flange size on the normalized distance between the origin to the intersection of the dividing streamline and the central axis is not less important than the influence on the normalized distance between the stagnation point and the central axis.

\section{ACKNOWLEDGMENT}

$\mathrm{T}$ his research was supported by the Institute of Occupational Safety and Health, Council of Labor Affairs of Taiwan.

\section{REFERENCES}

1. Dalla Valle, J.M.: "Studies in the Design of Local Exhaust Hoods." Sc.D. diss. Harvard University, 1930.

2. Dalla Valle, J.M.: Exhaust Hoods, pp. 21-48. New York: Industrial Press, 1945.

3. Dalla Valle, J.M., and T. Hatch: Studies in the design of local exhaust hoods. Trans. ASME 54:31-37 (1932).

4. Silverman, L.: Fundamental factors in the design of lateral exhaust hoods for industrial tanks. J. Ind. Hyg. Toxicol. 23:187-266 (1941).

5. Silverman, L.: Centerline velocity characteristics of round openings under suction. J. Ind. Hyg. Toxicol. 24:259-266 (1942).

6. Silverman, L.: "Fundamental Factors in the Design of Exhaust Hoods." Sc.D. diss., Harvard University, 1943.
7. American Conference of Governmental Industrial Hygienists $\left(\right.$ ACGIH $\left.^{\circledR}\right)$ : Industrial Ventilation-A Manual of Recommended Practice, 19th ed., pp. 4-1-4-21. Lansing, Mich.: American Conference of Governmental Industrial Hygienists, 1986.

8. Garrison, R.P.: Centerline velocity gradients for plain and flanged local exhaust inlets. Am. Ind. Hyg. Assoc. J. 42:739-746 (1981).

9. Braconnier, R.: Bibliographic review of velocity fields in the vicinity of local exhaust hood openings. Am. Ind. Hyg. Assoc. J. 49:185-198 (1988).

10. Garrison, R.P.: Velocity calculation for local exhaust inlets-graphical design concepts. Am. Ind. Hyg. Assoc. J. 44:941-947 (1983).

11. Garrison, R.P.: Velocity calculation for local exhaust inlets-empirical design equation. Am. Ind. Hyg. Assoc. J. 44:937-940 (1983).

12. Ellenbecker, M.J., R.J. Gempel, and W.A. Burgess: Capture efficiency of local exhaust ventilation systems. Am. Ind. Hyg. Assoc. J. 44:752-755 (1983).

13. Flynn, M.R., and M.J. Ellenbecker: The potential flow solution for air flow into a flanged circular hood. Am. Ind. Hyg. Assoc. J. 46:318-322 (1985).

14. Flynn, M.R., and M.J. Ellenbecker: Capture efficiency of flanged circular local exhaust hoods. Ann. Occup. Hyg. 30:497-513 (1986).

15. Flynn, M.R., and M.J. Ellenbecker: Empirical validation of theoretical velocity fields into flanged circular hoods. Am. Ind. Hyg. Assoc. J. 48:380389 (1987).

16. Flynn, M.R., and C. Miller: Comparison of models for flow through flanged and plan circular hoods. Ann. Occup. Hyg. 32:373-384 (1988).

17. Conroy, L.M., M.J. Ellenbecker, and M.R. Flynn: Prediction and measurement of velocity into flanged slot hoods. Am. Ind. Hyg. Assoc. J. 49:226-234 (1988).

18. Alenius, S., and A. Jansson: Air Flow and Particle Transport into Local Exhaust Hood -A Verified Computer Mode, p. 34. Solna, Sweden: National Institute of Occupational Health, 1989.

19. Heinsohn, R.J.: Industrial Ventilation: Engineering Principles, pp. 360 428. New York: John Wiley \& Sons, 1991.

20. Yuan, S.W.: Foundations of Fluid Mechanics, pp. 224-231. Englewood Cliffs, N.J.: Prentice Hall, 1967.

21. Currie, I.G.: Fundamental Mechanics of Fluids, pp. 155-160. New York: McGraw-Hill, 1974.

22. Huang, R.F., J.L. Chen, Y.-K. Chen, C.-C. Chen, W.-Y. Yeh, and C.-W. Chen: The capture envelope of a flanged circular hood in cross drafts. Am. Ind. Hyg. Assoc. J. 62:199-207 (2001).

23. Huang, R.F., S.Y. Sir, Y.-K. Chen, W.-Y. Yeh, C.-W. Chen, and C.-C. Chen: The capture envelope of a flanged circular hood in cross drafts. Am. Ind. Hyg. Assoc. J. 62:563-572 (2001).

24. Flagan, R.C., and J.H. Seinfeld: Fundamentals of Air Pollution Engineering, pp. 290-357. Englewood Cliffs, N.J.: Prentice Hall, 1988. 